مجلة كلية التربية الرياضية - جامعة بغداد * المجلا الثامن والعثرون * العدد الرابع * لسنة

\title{
دراسة مقارنة لفاعلية درس التربية الرياضية بين ثربية الكرخ الأولى والثانية في محافظة بغداد دهن
} م.د. ثامر حماد رجه م.م. عمار فليح رميح

\section{ه 1437}

\section{مستخلص البحث باللغة العربية.}

تعتمد مديريات تربية الكرخ (الاولى، الثانية) في بغداد على تطوير الطلاب ورفع إمكاناتهم المعرفية

والوجدانية والنفحركية من خلال المنهاج الدراسي والذي يجب أن يتصف بالثمولية والتكامل، الذي يعد درس التربية الرياضية جزءاً هاماً من هذا المنهاج، إذ يستطيع الطالب من خلاله تحقيق الكثير من اهدافه بالتكامل العقلي والبدني والنفسي وتحفيزه على فاعلية الانجاز والابتكار والإبداع عبر تطبيق مفردات الدرس بالثكل الأمتل، والأخذ على عاتق الإدارة التربوية للمدرسة توفير كافة الإمكانات الإدارية والمادية والمالية والأماكن المخصصة لها ودعم الكوادر التدريسية المتخصصة في إنجاح العملية التعليمية وتحقيق الدرس بفاعلية. وبالرغم من الدعوات المستمرة التي تحث على تفعيل دور الرياضة المدرسية إلا إن هناك ضعف في تطبيقها، ومن خلال الاطلاع على واقع بعض المدارس لمحافظة بغداد والاتصال المباشر مع مدرسي التخصص الرياضي، الذي غالباً ما يشكو من قلة الإمكانات المادية والمالية فضلاً عن تفاضل المواد الدراسية الأخرى واستغلال الأوقات المخصصة لدرس التربية الرياضة في استكمال المنهاج الدراسي، مما ادى في ضعف النشاط الرياضي. لذا بات من الواجب الوقوف على فاعلية درس التربية الرياضية ومدى توافر المعايير اللازمة في إنجاحه ودرجة إمكانية التطبيق في مدارس تربيات الكرخ الأولى والثانية لدحافظة بغداد خلال العام الدراسي. إذ نم إعداد استبانه تضمنت مجموعة من المحاور للتعرف على درجة فاعلية نطبيق درس التربية الرياضية والفروق في درجات تطبيقه لمدارس تربيات بغداد الكرخ الأولى والثانية. ونم تحديد عينة البحث من مدرسي التخصص الرياضي في المتوسطات والاعداديات للبنين التابعة لهذه المديريات. ونم التطرق إلى مجموعة مفاهيم لفاعلية درس التربية الرياضية ودور الإدارات المدرسية في دعمها على وفق أهداف درس التربية الرياضية الواجب نوافرها، وواجبات المدرس في تفعيل هذا الدرس والمعوقات التي تحول دون ذلك، فضلاً عن الاستعانة بالدراسات السابقة التي تطرقت لهذا الموضوع. ولتحقيق أهداف الدراسة استُخدم المنهج الوصفي لملائمته وطبيعة المشكلة، وحدد مجتمع الدراسة واختير عينة البحث منها والتي بلغت (123) مدرس، موزعة على نربية الكرخ الأولى والثانية وبحسب النسبة المئوية المعتمدة (30\%). تم وضع استبانة انتملت على (5) محاور، واعد لها مجموعة من الفقرات الدالة عليها (56) فقرة وزعت عليها بحسب آراء الخبراء المعتمدين والنسبة المئوية للاتفاق على صلاحيتها (80\%) للصدق الظاهري، ودرجة الثبات من خلال معادلة الفاكرمباخ 
مجلة كلية التربية الرياضية - جامعة بغداد * المجلا الثامن والعثرون * العدد الرابع ** لسنة

والذي بلغ نسبته (0.946) وهي نسبة مرتفعة للتعبير عن ثبات فقرات الاستبانة بوجود انساق ودقة في الأداة. وتم نوزيع الاستبانة على عينة الدراسة في المدة المحصورة بين 2016/3/24 ولغاية 2016/5/18. واعتمدت الحقيبة الإحصائية (spss) الاستبانة نتائج (غير دالة) إذ كانت المعنوية الحقيقية اكبر من مستوى الدلالة مما يثبر إلى عدم تطبيق درس التربية الرياضية بفاعلية. فضلاً عن ذلك لم نظهر هناك فروق معنوية بينهما، إذ يعتمد الطرفان على نفس اللوائح والتعليمات والتمويل المالي مما اظهر عدم نجاح فاعلية التطبيق بالثكل الأمتل. وتبين استتاجات الدراسة ضعف الجهاز التقويمي والمعايير اللازمة لذلك، وقلة الإمكانات المتاحة لتفعيله. وأوصت الدراسة بالأخذ بنظر الاعتبار آراء المستقيدين بشكل مستمر لدعم وتطوير الرياضة المدرسية، واعتماد مناهج مخصصة بها أسوة بباقي المواد الدراسية، والحث على المشاركات والاندماج مع الجهات المناظرة لتحسين العلاقات والاتصال لتبادل النقافات والخبرات الرياضية بشكل دوري.

\section{Abstract.}

\section{Comparative Study Of Physical Education Lesson Effectiveness Between Al - Karkh $1^{\text {st }}$ and $2^{\text {nd }}$ Education In Baghdad Governorate}

The importance of the research lies in designing a group of axes to identify the degree of physical education lesson application effectively as well as the difference in application degrees between the $1^{\text {st }}$ and $2^{\text {nd }}$ Kurk educational schools. The subjects of the research were physical educators of secondary and preparatory schools for boys. The researchers used the descriptive method on (123) physical educator. The questionnaire included 5 axis each ax consist of 56 item. The reliability of the questionnaire is $80 \%$ while reliability was 0.946 according to Fakurmbak formula. The questionnaire was distributed from 24/3/2016 till 18/5/2016.

The data was collected and treated using proper statistical operations. The results showed significant statistical differences in not using physical education program effectively as well as no significant differences between controlling and experimental groups because both groups depend on the same regulations and rules. The researcher recommended taking the points of view of individuals to develop school sport as well as using standard programs in teaching physical education. Finally they recommended participating with other types of schools to develop cultural relationships and sport expertise periodically. 


\section{1- 1 - 1اباب الأول: التعريف بالبحث:}

1-1

تعد التربية إحدى الركائز الأساسية للهجتمع والتي لها تأثير كبيراً في عقول وتصرفات الطلبة وتتمية شخصياتهم وقدراتهم العلمية والبدنية والنفسية وتكيفها مع المستجدات والتحديات التي يفرضها التطور التكنولوجي في جميع مجالات الحياة. إن للمدرسة أدوار متعددة في تزويد الطالب بالمعرفة الفاعلة وإكسابهم القيم والاتجاهات والمهارات لتمكنهم من الموائمة مع مجتمعاتهم والإسهام في تطورها. وبما إن درس التربية الرياضية احد العناصر الفاعلة في التربية الحديثة ومن العوامل المهمة في تحقيق التوازن وتكوين شخصبة الطالب وإعداده بشكل متكامل، بوصفه المحرك والداعم الأساس للحركة الرياضية، ولما له من اثر في البناء الفكري والجسمي ووضع الطالب على الخطوات الأولى لتحسين الأداء في المحافل الرياضية المدرسية. إذ إن مديرية تربية بغداد الكرخ (الاولى، الثانية) تعتمد في تطوير الطلاب ورفع إمكاناتهم المعرفية والوجدانية والنفسحركية من خلال المنهاج الدراسي والذي يجب أن يتصف بالثمولية والتكامل، الذي يعد درس التربية الرياضية جزءاً هاماً من هذا المنهاج، إذ يسنطيع الطالب من خلاله تحقيق الكثير من اهدافه بالتكامل العقلي والبدني والنفسي وتحفيزه على فاعلية الانجاز والابتكار والإبداع عبر تطبيق مفردات الدرس بالثكل الأمتل، والأخذ على عاتق الإدارة التربوية للمدرسة نوفير كافة الإمكانات الإدارية والمادية والمالية والأماكن المخصصة لها ودعم الكوادر التدريسية المتخصصة في إنجاح العملية التعليمية وتحقيق درس التربية الرياضية بفاعلية، بوصفهم المسؤولين عن تطبيق

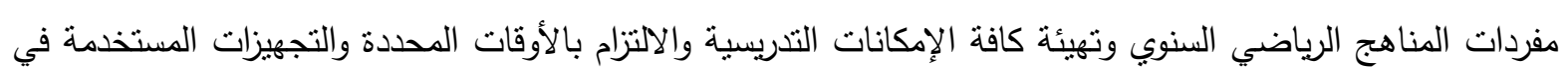
تحقيق اهداف الدرس على وفق معايير وأسس تشبع حاجات ورغبات الطالب في هذه المرحلة العمرية لما لها من خصوصية في التطوير الجسمي والعقلي والحركي والنفسي، والتي يجب أن تنتغل بالثكل الصحيح لتحسين القدرات البدنية وتتشيط العمليات العقلية في التفكير والايجابي وتفريخ الطاقات والحركة المفرطة التي تفرضها هذه المرحلة، فضلاً عن ذلك يمكن من خلالها اكتثاف المواهب الرياضية واستثمارها في التحسين المستمر والتطوير من قدراتهم لتحقيق الانجاز الرياضي وإعداده للمستقبل على وفق أساليب وطرائق حديثة للوصول إلى المرامي المنشودة.

\section{2-1}

بالرغم من الدعوات المستمرة في الندوات والمؤتمرات العلمية التي تحث على تفعيل دور الرياضة المدرسية

إلا إن هنالك ضعف في تطبيق درس التربية الرياضية في الددارس المتوسطة والإعدادية للبنين، إذ لوحظ من خلا بل المتابعة والمقابلات الثخصية لبعض كوادر التخصص الرياضي هناك تلكأ في تطبيقه. ومن خلال الاطلاع على الواقع في بعض المدارس لمحافظة بغداد والاتصال المباشر مع مدرسي التخصص الرياضي، الذي غالباً ما يشكو من قلة الإمكانات المادية والمالية فضلاً عن تفاضل المواد الدراسية الأخرى واستغلال الأوقات المخصصة له في استكمال المنهاج الدراسي، مما ادى الى وجود مشكلة حقيقية في ضعف النشاط الرياضي. لذا بات من الواجب الوقوف على فاعلية درس التربية الرياضية ومدى الاهتمام المتوافر لدى الإدارات في تفعيله والمحاور الواجب توافرها واللازمة في 
مجلة كلية التربية الرياضية - جامعة بغداد ** المجلا الثامن والعشرون ** العدد الرابع ** لسنة

إنجاحه ودرجة إمكانية النطبيق بالثكل الامتل في مدارس تربيات الكرخ الأولى والثانية لمحافظة بغداد خلال العام الدراسي.

3-1

1. إعداد استبانة لفاعلية تطبيق درس التربية الرياضية لمدارس تربية بغداد الكرخ الأولى والثانية في محافظة بغداد.

2. التعرف على درجة فاعلية تطبيق درس التربية الرياضية لمدارس تربية بغداد الكرخ الأولى والثانية في محافظة بغداد. 3. التعرف على الفروق في درجات فاعلية تطبيق درس التربية الرياضية لمدارس تربية الكرخ الأولى والثانية في محافظة بغداد. 4-1 لا توجد فروق معنوية في درجات تطبيق درس التربية الرياضية لمدارس تربية الكرخ الأولى والثانية في محافظة بغداد.

5-1 1-5-1-1 المجال البشري: مدرسي التخصص الرياضي لمدارس تربية الكرخ الأولى والثانية للبنين في محافظة بغداد. 2-5-1 المجال الزماني: للمدة من 2016/1/5 لغاية 2016/5/28. 3-5-1 المجال المكاني: المدارس المتوسطة والإعدادية لتربية الكرخ الأولى والثانية للبنين في محافظة بغداد.

6-1

الفاعلية: القدرة والكفاءة التي يوصف فيها أداء معين طبقاً لمعايير او مجالات او محاور محددة مسبقاً لتحقيق هدف أو فعل محدد (17:24). درس التربية الرياضية: وهو العمود الفقري في نتقيف الطلبة وتربيتهم من خلال الأنشطة البدنية والمعرفية والنفسركية والنقافية والترويحية ليتحملوا المسؤولية نحو أنفسه وحياتهم الثخصية والاجتماعية وتتشئتهم على استثمار النشاط الحر وأوقات الفراغ واكتساب المهارات الرياضية (3:17). 
2- 2 - الباب الثاني: الدراسات النظرية والسابقة: 1-2

فاعلية درس التربية الرياضية: 1-2 1-1

يعد درس التربية الرياضية الوسيلة الأكثر فاعلية وتأثثرا لبناء النشء والثباب بناءً متكاملاً في مختلف السلوك الإنساني والإسهام في تحقيق معدلات بناء شخصية الطالب واكتسابه القدرة على المشاركة الايجابية واكتشاف المواهب وتفريغ الطاقات في الاتجاه الصحيح وتوفير السلامة الجسمية والعقلية والنفسية والاجنماعية والخلقية، من اجل المواطنة الصالحة والاندماج في المجتمع مستقبلا، فضلاً عن التشجيع عل الأنشطة الحرة واستثمار أوقات الفراغ وتطوير المهارات الرياضية المكتسبة وتسخير الجهد التعاوني في إنجاح هذا النشاط كجزء من المهام التربوية (14:24). إذ تعد التربية الرياضية بمثابة منظومة تربوية اقتصادية نستثر فيها القوة البشرية للإدارة التربوية وتفعيله بالثكل الصحيح لتصبح إحدى الأعمدة الداعمة للتقام والرقي وزيادة الإنتاج....لذا عدت الرياضة إحدى الجوانب الاقتصادية العالمية والمنتجة لكافة الإمكانات الرياضية عبر عمليات النسويق للطاقات الرياضية والأبطال والمواهب ومن ثم استثمارهم في دعم الموارد المالية للدولة، لاعم القطاعات التعليمية وتحسين مستوى الطلبة في كافة الاتجاهات التتموية.... فالولايات المتحدة على سبيل المثال حققت مردوداً مالياً في عام (2000) من المشاركات والبطولات الرياضية بشكل عام ما يقارب (212.50 \$) مليون دولار ، مما جعله جزاً هاماً من مفاصل الدولة (6:42 ـ 43).

\section{2-1-2 2 دور المدرسة في دعم فاعلية درس التربية الرياضية:}

تعد الإدارة المدرسية إحدى المقومات والعوامل الهامة في تفعيل الرياضة المدرسية، والإسهام في إنجاح المنهاج الرياضي عبر الفصل الدراسي، لما لها الدور الكبير في ضبط عملية توزيع الحصص الأسبوعية الخاصة بدرس التربية الرياضية وتتظيم الأوقات الدحدة ما بين الدروس الأخرى وتفعيل النشاطات الداخلية والخارجية وتوفير كافة الإمكانات وتوظيفها في تطبيق هذا المنهاج من قبل الكوادر المتخصصة لكافة المراحل الدراسية. وهناك بعض الأسس الهامة الني يجب إنباعها من اجل دعم فاعلية الدرس ومنها كالآتي (2:20):

$$
\text { • • اعتماد جودة التحسين المستمر لكافة المفاصل في الإدارة المدرسية. }
$$$$
\text { • نشر نقافة التميز في الأداء الرياضي والإثابة والاعم المعنوي. }
$$$$
\text { • التجديد والتنريب المستمر لعمل الكوادر التدريسية في مادة التخصص الرياضي. }
$$$$
\text { توافر الإمكانات المتاحة لتفعيل النشاط الرياضي. }
$$$$
\text { التواصل مع الجهات العليا للتعزيز والدعم الايجابي. }
$$

• الاتصال المباشر وغير المباشر بالجهات المناظرة وتفعيل دور المنافسة للبطولات والمشاركات الرياضية. • التطوير المستمر للأنشطة الخارجية والداخلية على حدً سواء. • اعنماد التغذية الراجعة في تذليل العقبات والصعوبات. 
مجلة كلية التربية الرياضية - جامعة بغداد * المجلا الثامن والعثرون * العدد الرابع ** لسنة

3-1-2

من اجل الحصول على درس التربية الرياضية بشكل ناجح ومنظم ذو مردودات ايجابية تخدم الأهداف المتوخاة منه، لابد من بذل الجهود المضنية في إعداد الطلبة على وفق تخطيط استراتيجي فعال يمكنه من التفاعل الايجابي مع الدرس، فضلاً عن القدرة على تعديل السلوك بما يتواءم مع الأسس التربوية والاجتماعية ومراعاة الفروق الفردية لمستوى الأداء في اختيار النشاطات الحركية المنوعة بسحب المراحل الدراسية والإمكانات المتاحة في تطبيق الدرس، إذ إن نجاح درس التربية الرياضية يتوقف على حسن الإعداد والإخراج لتحقيق الغايات المنشودة منه عبر استعراض مفصل لكافة الأعمال المناطة بمدرس التخصص الرياضي وتحديد الأهداف العامة والخاصة لتحقيق الانجاز بحسب الوقت المحدد لها خلال العام الدراسي. ومن أهم الاستراتيجيات المتبعة هي كالآتي (10:20 ـ 21): • استراتيجيات التدريس المباشر في تحديد المحتوى التعليمي والأنشطة المستخدمة من قبل المدرس. • استراتيجية نظام المحطات في اختيار الأنشطة على وفق الإمكانات المتوافرة في المدرسة. • التعلم الاتقائي للحصول على درجة التميز في الأداء والانتقال إلى الأهم والأصعب على شكل فردي أو جمعاي أو ما بين المجاميع.

\section{2-1-2 أهداف درس التربية الرياضية:}

بما إن أهداف التربية الحديثة أصبحت تماثي وتنساير الأهداف المرسومة لفلسفة الدولة في كل مظاهرها الاجتماعية والثقافية والسياسية، فان أهداف المنهاج الرياضي يجب تتحقق هذا الأمر بوصفها أكثر المناهج لها القدرة على تحقيق أهداف المجتمع لما فيه من فعاليات ونشاطات منوعة تزيد من الخبرات الثخصية والقدرة على التعامل مع الآخرين (15:119 ـ 120). إن التربية الرياضية تهدف إلى تحقيق عدة أهداف أساسية طويلة الأمد تتبثق منها أهداف سلوكية متوسطة وقصيرة الأمد، يسعى مدرس التربية الرياضية إلى محاولة تحقيقها بأساليب وطرائق متعددة بحسب نوع النشاط والأماكن المتوافرة وإعداد الطلاب لكل مرحلة، عبر مجالات رئيسة وهي كالآتي (10:6 ـ 7):

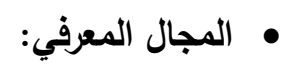

1. توعية الطلبة بالتغيرات الجسمية التي تحدث في هذه المرحلة. 2. تعليم الطلبة القوانين والخطط الخاصة باللالعاب الرياضية الموضوعة في المنهاج السنوي. 3. إكساب الطلبة الثقافة الرياضية العامة والفائدة الصحية والنفسية التي تتتج عن ممارستها. 4. تحقيق مستويات اللياقة البدنية والحركية وتتمية الأفكار بالاتجاه العلمي الصحيح. 5. إكساب الطلبة حب المواطنة والتخطيط للوصول إلى الأفضل. 
مجلة كلية التربية الرياضية - جامعة بغداد * المجلا الثامن والعثرون * العدد الرابع * لسنة

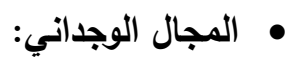

1. ت تطوير الدوافع الرياضية وتتمية ميولهم واتجاهاتهم وإثارة رغباتهم نحو مزاولة النشاط الرياضي. 2. تتمية روح المشاركة والاندماج مع الآخرين في المباريات والمسابقات والمهرجانات الداخلية والخارجية. 3. العمل بروح الفريق والتحلي بالروح الرياضية والاهتمام بالجانب الكثفي الإرشادي.

4. اكتشاف ذوي المواهب والقدرات الرياضية وإعطائهم الرعاية الكافية لتنميتها.

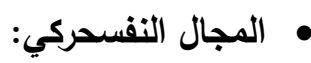

1. - 1 ت نطوير عمليات التوافق الحركي.

2. تعليم الطلبة مبادئ وأسس الحركات الرياضية وتطوبر الأداء بشكل متررج.

3. ممارسة الألعاب الرياضية المناسبة لأعمارهم في النثاطات اللاصفية وتتجيعهم بالثكل الايجابي. 4. تحقيق مستويات اللياقة البدنية والحركية تتمية الأداء المهاري لديهم.

\section{2-1-2 و واجبات المدرس في إدارة وتخطيط درس التربية الرياضية:}

يعد مدرس التربية من العناصر المهمة والفاعلة في عملية نوجيه الطلبة وتعليمهم وفقاً لأهداف تربوية واجتماعية وإنسانية بوصفه المنظم والمنسق للمنهاج الرياضي المطبق خلال العام الدراسي ونوظفيها في قنوات نظرية وعملية من اجل إنجاح النشاط الرياضي، والأخذ على عانقهم عدة واجبات يمكن ذكر البعض منها وهي كالآتي

• القدرة على القيادة الناجحة والإدارة الفاعلة لدرس التربية الرياضية وان يكون قدوة للآخرين ذو مظهر لائق

$$
\text { وأخلاقيات عالية. }
$$

• اتخاذ القرارات الحازمة في المواقف المتتوعة لإثبات فاعلية الأداء الرياضي في الدرس.

ه الاندماج والتعايش الأبوي مع الطلبة للتعرف على المعوقات الصعوبات التي تواجهم ومحاولة تذليلها.

تتمية حب الولاء للوطن والانتماء للجماعة والتحلي بالعلاقات الاجتماعية.

مراعاة الفروق الفردية من خلال التعامل في الأداء الرياضي مع الطلبة والابتعاد عن التمايز بينهم.

تشجيع الطلبة على السلوكيات والعادات الصحيحة.

وضع الخطط الخاصة بدرس التربية الرياضية على وفق المنهاج المحد الإمكانات المنوافرة.

إثراك الطلبة في التخطيط والتحضير للارس.

تتظيم البطولات والمسابقات والتنسيق مع الجهات المسؤولة خلال العام الدراسي.

إعداد الملاعب وتخطيطها بشكل قانوني.

صيانة الأجهزة والمعدات وتوفير وسائل المتانة والأمان فيها بشكل دوري.

تحضير السجلات والاستبانات الخاصة بإنجازات الطلبة. 
مجلة كلية التربية الرياضية - جامعة بغداد * المجلا الثامن والعثرون * العدد الرابع ** لسنة

• كتابة التقارير الدورية لفاعلية الطلبة وأدائهم الرياضي ومدى رغباتهم في الاستمرار والإبداع والتطور •

\section{-6-1-2 المعوقات التي تواجه فاعلية درس التربية الرياضية:}

هناك العديد من المعوقات التي تواجه درس التربية الرياضية مما يصعب تفعيله بشكل صحيح في العديد من المدارس التربوية، إذ إن الوقوف على كافة المشكلات وتذليلها خطوة نحو تحقيق الاتجاز ودعم الأنشطة الرياضية على وفق حول ومقترحات ناجعة تسمح في تفادي التحديات ومواجهتها وتحقيق الهدف العام للأداء الرياضي في مرحلة الدراسة الثانوية، ومن هذه المعوقات هي كالآتي (4:88 ـ 89):

• عدم توافر خطط فاعلة لتتفيذ المنهاج السنوي لدرس التربية الرياضية. • ق قلة الكوادر المتخصصة في بعض المدارس. • ضعف الدعم المادي والمعنوي من قبل الإدارة المدرسية.

• • • قلة توافر الأماكن الخاصة لنطيق درس التربية الرياضية.

• تجاوز الدروس النظرية الأخرى على ساعات المخصصة لدرس التربية الرياضية.

• تكليف مدرس التربية الرياضية بمهام إدارية خاصة بالمدرسة.

• الإعداد المتزايدة في بعض المدارس والذي لا يتتاسب مع حجم التجهيزات والأوقات المخصصة بالدرس.

• قلة المشاركات الخارجية والاندماج مع الجهات المناظرة وتوسيع النشاط الرياضي.

• المفهوم الخاطئ لبعض المدرسين وأولياء الأمسور إن الرياضية تلهي الطالب عن مهامه الدراسية.

• قلة الحصص المخصصة لدرس التربية الرياضية.

2-2 2 الدراسات السابقة:

1-2-2 واقع النشاط الرياضي اللاصفي الداخلي وسبل تطويره على مدارس المتوسطة للبنات في

بذاد. (11: دراسة فاتن)

هدفت هذه الدراسة إلى التعرف على واقع النشاط الرياضي في الددارس المنوسطة للبنات في محافظة

بغداد، واقتراح حلول للارتقاء بمستوى النشاط الرياضي الداخلي. إذ بلغت عينة الدراسة (68) مدرسة للتربية الرياضية في المداس المتوسطة للبنات من مجتمع الأصل والبالغ عدده (168) مدرسة تم اختيارها بالطريقة العشوائية وبنسبة مئوية بلغت (53.54\%) من المجتمع الأصلي. اعتمدت هذه الدراسة على تصميم استبانة احتوت على مجموعة من الأسئلة بلغت (27) سؤالاً، ونم تطبيق الإجراءات العلمية عليها، من ثم توزيعها على عينة الدراسة، وبعد الجمع والتفريخ للاستبانة تم نطبيق المعاملات الإحصائية عليها للحصول على نتائج الدراسة وتحقيق أهداف البحث. وتوصلت نتائج الدراسة إلى عدم وجود دليل ومنهاج ثابت لدرس التربية الرياضية، فضلاً عن إن أكثر مدرسات التخصص الرياضي ونسبة (57\%) 
مجلة كلية التربية الرياضية - جامعة بغداد * المجلا الثامن والعشرون * العدد الرابع * لسنة

يضعن مناهج لدرس التربية الرياضية بحسب قدراتهن وخبراتهم الثخصية، أما الحصص المخصصة للارس تبين إنها كافية من وجهة نظرة المدرسات.

2-2-2 معوقات تحقيق أهداف التربية الرياضية بدولة الإمارات العربية المتحدة (1: دارسة

إبراهيم).

هدفت هذه الدراسة إلى التعرف على المعوقات التي تحول دون تحقيق أهداف درس التربية الرياضية

لمدارس البنين في دولة الإمارات المتحدة، والوقوف على الدرجة الحاصل عليها كل مجال محدد في الإسنبانة. اعتمدت الدراسة المنهج الوصفي، وطبقت على عينة بلغ قوامها (32) مدرساً من كافة مناطق الدولة مستخدماً الطريقة العشوائية البسيطة، وحددت مجالات الإستبانة لجمع المعلومات المطلوبة في تحقيق أهداف الدراسة، مستخدماً الوسائل الإحصائية المناسبة في الحصول على نتائج الدراسة، وتوصلت إلى عدة نتائج منها إن الإدارات المدرسية لا تهنم بمدرس التخصص الرياضي كما هو الحال لباقي التخصصات الموجودة، فضلاً عن كثافة المنهاج الدراسي الذي لا يسمح بتطبيق الدرس بشكل صحيح وقلة الوقت المتاح خلال فترة الدوام اليومي، وقلة الاهتمام بالجوانب البدنية والمهارية لتحسين قابليات الطلاب في تطوير أدائهم الرياضي.

3-2-2

اتفقت الدراسة الحالية مع الدراسات السابقة في تطبيقها على المدارس الثانوية (المتوسطات والاعداديات)

للبنين وتحديد العينة بمدرسين التخصص الرياضي فيها، مستخدمين الدنهج الوصفي والاستبانة لتطبيق الدراسة، فضلاً عن اختياره الأدوات المناسبة لجمع المعلومات والاستفادة من الباب النظري في النعرف على الأدبيات والمراجع العلمبة المستخدمة، معتمداً عليها في تفسير النتائج الدراسة الحالية في ما توصلت إليه الدراسات السابقة، والاطلاع على كافة المحاور النظرية والعملية التي تخدم الهدف المطلوب. أما أوجه الاختلاف فتبين إن دراسة إبراهيم استخدمت مجتمع مدارس البنات في تطبيق الدراسة أما الدراسة الحالية اعتمدت مدارس البنين في تطبيقها. فضلاً عن اعتماد الدراستين على مدارس المتوسطة فقط أما الدارسة الحالية اعتمدت المرحلتين المتوسطة والإعدادية معاً.

\section{3-3 الباب الثالث: منهج الدراسة وإجراءاتها الميدانية: 1-3}

من اجل تحقيق أهداف الدراسة استخدم الباحث المنهي الوصفي بالأسلوب المسحي لملائمته وطبيعة

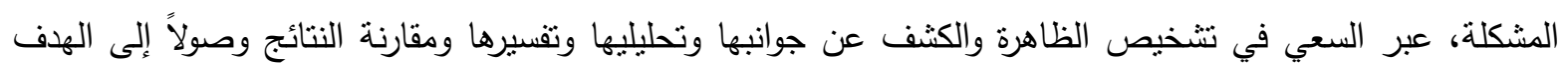
المراد تحقيقه. 
مجلة كلية التربية الرياضية - جامعة بغداد * المجلا الثامن والعثرون * العدد الرابع ** لسنة

2-3

حُدد مجتمع الدراسة من مدرسي التخصص الرياضي في المتوسطات والاعداديات لتربيات الكرخ (الأولى، الثانية) للبنين في محافظة بغداد للعام الدراسي 2016/2015، بواقع (220) مدرسة، بواقع (97) مدرسة في تربية الكرخ الأولى، و (123) مدرسة في تربية الكرخ الثانية، نوزع فيها (413) مدرس. ومن ثم نم اختيار الدارس التي أجريت عليها الدراسة والتي بلغت (66) مدرسة، بواقع (29) مدرسة في تربية الكرخ الأولى و(37) مدرسة في تربية الكرخ الثانية، بالطريقة العشوائية البسيطة وبنسبة مئوية بلغت (30\%). وتم تحديد عينة الدراسة بـ(123) من المدرسين، بواقع (56) مدرس في تربية الكرخ الأولى، و (67) مدرس في تربية الكرخ الثانية، وبنفس النسبة المئوية التي تم تحديدها من

المدارس المختارة، وكما في جدول (1).

جدول (1)

يبين عدد المدارس والمدرسين بالنسبة المئوية

\begin{tabular}{|c|c|c|c|c|c|c|c|}
\hline عدد المدرسين & $\begin{array}{l}\text { النسبة } \\
\text { \%30 }\end{array}$ & عدد المدرسين & عدد المدارس & النسبة 30\% & عدد المدارس & المديريات & $ت$ \\
\hline 56 & 56.4 & 188 & 29 & 29.1 & 97 & الكرخ الأولى & 1 \\
\hline 67 & 67.2 & 224 & 37 & 36.9 & 123 & الكرخ الثانية & 2 \\
\hline 123 & 123.6 & 413 & 66 & 66 & 220 & المجموع & \\
\hline
\end{tabular}

3-3 أدوات الاراسة المستخدمة:

• • - مصادر العربية والأجنبية.

• المقابلات الثخصية.

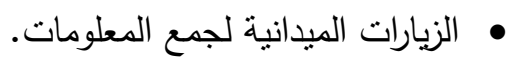

هبكة المعلومات (الانترنت).

• الاستبانة لجمع البيانات.

4-3 خطوات تنفيذ الدراسة:

3-4-3 1 إعداد الاستبانة:

تعد الاستبانة من الأدوات المهمة لجمع المعلومات والبيانات بشكل منظم لتحقيق أهداف الدراسة، إذ قام الباحث بعد مقابلة واستشارة بعض المختصين (انظر ملحق 1) في مجال التخصص الرياضي ومدراء المدارس والمشرفين على هذه الأنشطة الطلابية فضلاً عن الأدبيات والدراسات السابقة للاطلاع على الدحاور والفقرات الملمة بموضوعة الدراسة، نم وضع استبانة اثتملت على (5) محاور، وصاغ لها مجموعة من الفقرات الدالة عليها. وبعد إعداد المحاور 
مجلة كلية التربية الرياضية - جامعة بغداد * المجلا الثامن والعثرون * العدد الرابع * لسنة

والفقرات والبالغ عددها (64) فقرة، تم عرضها على السادة الخبراء (انظر ملحق 2) والبالغ عددهم (14) خبير في مجال الإدارة والتتظيم وطرائق التدريس والعلوم التربوية والنفسية والقياس والتقويم والمشرفين المختصين في مجال التخصص الرياضي في وزارة التربية، من اجل التقويم والتعديل والاتفاق على صياغة الفقرات بشكل علمي يخدم هدف الدراسة. ومن ثم إبداء الرأي في صلاحية مقياس التقدير اللفظي المستعمل في الاستبانة والذي نم تحديده بحسب مقياس ليكرت الخماسي. "لسهولة استعماله وارتفاع درجة الثبات والصدق للقياس إذ نتيح للمستجيب أن يعبر عن اتجاهه بالنسبة لكل فقرة وتقليل أعمال التخمين والصدفة في الإجابات" (16:88). وقد أبدا الخبراء أراءهم وملاحظاتهم على فقرات الاستبانة، وتم حذف بعض الفقرات لعدم صلاحيتها (8) فقرة، وتعديل وتصحيح بعض الألفاظ في باقي الفقرات المستعلة في الاستبانة. إذ اعتمد الخبراء كافة المحاورة وحدد الفقرات التابعة لها والبالغ عددها (56) فقرة، وكما في جدول (2).

جدول (2)

يبين المحاور المستعملة وعدد الفقرات التابعة لها

\begin{tabular}{|c|c|c|c|c|c|}
\hline النسبة \% & عدد التعديل الفقرات & النسبة \% & قدبل التعديل الفقرات & محاور الاستبانة & $ت$ \\
\hline 25 & 14 & 23.437 & 15 & الإدارة المدرسية & 1 \\
\hline 16.071 & 9 & 17.187 & 11 & الميزانيات الداعمة للنشاط الرياضي & 2 \\
\hline 19.642 & 11 & 20.312 & 13 & التخطيط لدرس التربية الرياضية & 3 \\
\hline 21.428 & 12 & 20.312 & 13 & الأبنية والتجهيزات المتوافرة & 4 \\
\hline 17.857 & 10 & 18.75 & 12 & المشاركات والجهات المستقيدة & 5 \\
\hline$\% 100$ & 56 & $\% 100$ & 64 & & \\
\hline
\end{tabular}

3-3-3 الأسس العلمية للاستبانة:

2-4-3

تم التحقق من صدق الاسنبانة عبر مجموعة الخبراء (14 خبير) في إبداء أراءهم في صلاحية المحاور ومدى انتماء كل مجموعة من الفقرات للمحور التابعة له، واعتمدت النسبة المئوية (80\%) فأكثر في الموافقة على الفقرة باتفاق الخبراء. "فقد أثنار (Ebel) إن أفضل طريقة للتأكد من صدق الظاهرة لأداة القياس أن يقدر ذلك مجموعة من الخبراء المختصين مدى تمثيل الفقرات للصيغة المطلوب قياسها" (18:554).

2-2-3-3

تم التحقق من ثبات الاستبانة بعد توزيعها على (30) مدرس خارج عينة الدراسة، إذ تم استعمال معامل الفاكروباخ والذي بلغ نسبته (0.946) وهي نسبة مرتفعة للتعبير عن ثبات فقرات الاستبانة بوجود اتساق ودقة في الأداة وكما في جدول (3). 
مجلة كلية التربية الرياضية - جامعة بغداد * المجلا الثامن والعثرون * العدد الرابع ** لسنة

جدول (3)

يبين معامل الفاكرمباخ للمحاور والاستبانة ككل

\begin{tabular}{|c|c|c|c|}
\hline معامل الفاكرمباخ & عدد الفقرات لكل محور & محاور الاستبانة & 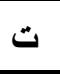 \\
\hline 0.875 & 14 & الإدارة المدرسية & 1 \\
\hline 0.844 & 9 & الميزانيات الداعمة للنشاط الرياضي & 2 \\
\hline 0.799 & 11 & التخطيط لدرس التربية الرياضية & 3 \\
\hline 0.979 & 12 & الأبنية والتجهيزات المتوافرة & 4 \\
\hline 0.921 & 10 & المشاركات والجهات المستقيدة & 5 \\
\hline 0.946 & 56 & ع الفقرات والدرجة النهائية للثبات & \\
\hline
\end{tabular}

3-4-3 التجرية الاستطلاعية:

تم اجراء التجربة الاستطلاعية في تاريخ 2016/3/10، على عينة قوامها (30) مدرس من المجتمع

الاصل خارج العينة الاساس، للتعرف على كافة المعوقات والصعوبات والثروط الواجب توافرها عند التطبيق، فضلاً عن أعداد فريق العمل المساعد (انظر ملحق 3) في نوزيع واسترجاع الاستبانات لجمع المطلومات والبيانات التي تخدم

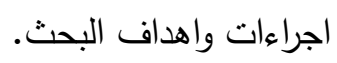

4-4-3

نم توزيع الاستبانة على عينة الدراسة من مدرسي التخصص الرياضي في منوسطات واعداديات تربية الكرخ الأولى والثانية للبنين في محافظة بغداد للمدة المحصورة بين 2016/3/24 ولغاية 2016/5/18. وبعد الانتهاء من خطوات الدراسة تم جمع البيانات وترتيبها في جداول منظمة لإخضاعها للمعالجة الإحصائية.

5-3

تم استخدام نظام الحقيبة الإحصائية (spss) في معالجة البيانات والحصول على نتائج الدراسة. 
مجلة كلية التربية الرياضية - جامعة بغداد * المجلد الثامن والعثرون ** العدد الرابع * لسنة

4- الباب الرابع: عرض النتائج وتحليها ومناقشتها: 4-1 ع عرض النتائج الكلية لمحاور الاستبانة:

للتعرف على درجة فاعلية تطبيق درس التربية الرياضية في مدارس تربية بغداد الكرخ الأولى والثانية، والوقوف على إجابات العينة للمحاور المستهدفة في الاستبانة، عد الباحث إلى حساب الوسط الحسابي والاتحراف المعياري والوسط الحسابي المرجح والأهمية النسبية وقيمة (ت) المحسوبة والمعنوية الحقيقية لكل محور من محاور الاستبانة وكما في جدول (4).

جدول (4)

يبين نتائج الاختبار التائي لعينة واحدة للمحاور الرئيسة

\begin{tabular}{|c|c|c|c|c|c|c|c|c|}
\hline لادلادئوى & لمعنيقية المنة & لمحسوبة & الفرضط & $\varepsilon^{ \pm}$ & سن & لغترات & لمحور الرئيس & $ت$ \\
\hline غير د اللة & 0.641 & 1.367 & 42 & 8.375 & 26.365 & 14 & الإد ارة المدرسية" & أولا \\
\hline غير د الة & 0.376 & 0.264 & 27 & 4.676 & 17.743 & 9 & المبزانيات الداعة للنشاط الرياضي & ثنانباً \\
\hline غير د الة & 0.499 & 0.358 & 33 & 6.778 & 21.389 & 11 & التخطبط لدرس التزبية الرياضية & 政 \\
\hline غير دالة & 0.537 & 1.269 & 36 & 7.986 & 23.154 & 12 & الأبنبة والنجهيزات المنوافرة & 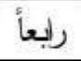 \\
\hline غير دالة & 0.397 & 0.552 & 30 & 6.264 & 20.943 & 10 & المشُاركات والجهات المسنقبدة: & خامساً \\
\hline
\end{tabular}

معنوي إذا كانت المعنوية الحقيقية (sig) > 0.05 عند درجة حرية 122.

يتبين من جدول (4) إن المحاور الرئيسة لفاعلية نطبيق درس التربية الرياضية غير دالة إحصائيا. إذ أظهرت نتائج البحث القيمة المعنوية الحقيقية (sig) للمحاور الرئيسة اكبر من مسنوى الدلالة (0.05)، مما يثير إلى إن فاعلية درس التربية الرياضية غير محققة في مدارس تربيات الكرخ الأولى والثانية. إذ إن درس التربية الرياضية لم يحقق الأهداف والغايات المحددة له خلال السنة الدراسية، وذلك لعدم الاهتمام الحقيقي في تفعيل نشاطاته من قبل المدارس وتفضيل الدروس الأخرى عليه بوصفها دروس أكثر أهمية لتعليم الطلاب وزيادة معلوماتهم بحسب وجهة نظرهم، فضلاً عن تكليف أساتذة التخصص الرياضي بأغلب الأمور الإدارية والخدمية في الددرسة وابتعاده عن الالتزام في نطبيق النشاط الرياضي في المدارس والاعتماد على بعض الفعاليات الرياضية البسيطة كدرس تروحي للطلبة عبر الدروس الأخرى وبحصص غير كافية لإنجاح العملية التعليمية الخاصة بالرياضة المدرسية، فضلاً عن عدم تحديد منهاج رئيس يعتمد في تطبيقه خلال العام الدراسي لمرحلتي المتوسطة والاعدادية للبنين، والاعتماد على مدرس التربية الرياضية باختيار الفعاليات التي برتئيها بحسب ما متوافر من التجهيزات أو الأوقات المحددة من قبل إدارة المدرسة. وهذا ما يتفق مع الدراسات السابقة (فاتن 1993) ودراسة (إبراهيم 2001)، والتي بينت عدم وجود منهاج ثابت لدرس التربية الرياضية والاعتماد على الخبرات الثخصية للمدرس وما توافر من قدراته يمكن الركون إليها في نطبيق الدرس بشكل صحح، 
مجلة كلية التربية الرياضية - جامعة بغداد * المجلا الثامن والعثرون * العدد الرابع ** لسنة

فضلاً عن عدم اهتمام المدرسة بمدرسي التخصص الرياضي وتفضيل باقي المواد الأخرى على الحصة المخصصة للارس، وقلة نوافر المواد والتجهيزات الرياضية والملاعب المخصصة لذلك.

2-4 عرض نتائج فقرات الاستبانة بحسب المحور التابعة له: للوقوف على مستوى تحقق درجة فاعلية نطبيق درس التربية الرياضية لتربية الكرخ الأولى والثانية في محافظة بغداد. من خلال أراء عينة البحث نحو الفقرات المحددة ضمن كل محور والتقدير اللفظي الذي تم الحصول عليه، عمد الباحث إلى استخراج المتوسطات الحسابية الانحرافات المعيارية والمتوسطات المرجحة لكل فقرة والأهية النسبية المحددة لها ومدى تباين إجابات العينة على الفقرات وهي كالآتي:

• أولا: الإدارة المدرسية: والمتضمن عدد الفقرات من (1- 14).

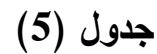

يبين نتائج الوسط الحسابي والانحراف المعياري والوسط المرجح والوزن المئوي لكل فقرة

\begin{tabular}{|c|c|c|c|c|c|}
\hline 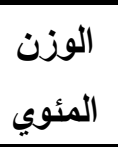 & الوسط & $\varepsilon^{ \pm}$ & سَن & الفقرات & 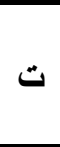 \\
\hline 50.24 & 2.512 & 0.834 & 2.34 & تعل المدرن المدرسة مع المديريات لأقامت دورات تدريبية لتحسين قدرات & \\
\hline 87.14 & 4.357 & 0.541 & 3.96 & 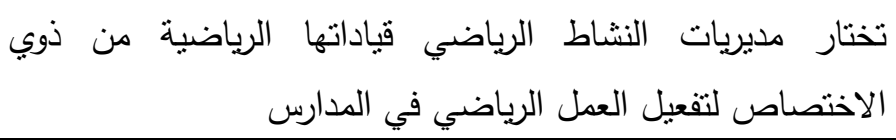 & \\
\hline 56.62 & 2.831 & 0.638 & 1.98 & تلعتمد الإدارة المدرسية على خطط فاعلة في تحسين برنامج الرياضة & \\
\hline 55.36 & 2.768 & 0.647 & 2.97 & الأحتقاظ بسجلات تقويمية للطلبة وتطورهم للأداء الرياضي خلال & \\
\hline 66.52 & 3.326 & 1.084 & 3.12 & المراجعة المستمرة لمنهاج الأنشطة الرياضية خلال السنة الدراسية & \\
\hline 70.88 & 3.544 & 0.462 & 3.85 & توثيق النجاحات الرياضية من قبل الإدارة المدرسية وتدعيمها & \\
\hline 48.24 & 2.412 & 0.886 & 2.32 & التطوير الأداء الرباضين المستمر للرياضة المدرسية عبر الخطط الناجعة والطموحة & \\
\hline 53.54 & 2.677 & 0.743 & 1.89 & تنبني الإدارة خطط وطرائق حديثة في عمليات التخطبط والتنظيم & \\
\hline 59.08 & 2.954 & 1.205 & 2.01 & تحديد اطر العمل بشكل واضح لتحقيق أهداف درس التربية & \\
\hline 46.46 & 2.323 & 0.642 & 2.15 & في تحسين درس التربية الرياضية & 10 \\
\hline
\end{tabular}


مجلة كلية التربية الرياضية - جامعة بغداد * المجلد الثامن والعشرون * العدد الرابع * لسنة

\begin{tabular}{|c|c|c|c|c|c|}
\hline 50.44 & 2.522 & 0.732 & 2.24 & نشر ثقافة التميز في الأداء الرياضي والإثابة والدعم المعنوي من & 11 \\
\hline 68.48 & 3.424 & 0.498 & 3.63 & خلال العام الدراسي في البطولات والمسابقات والتتسيق مع الجهات المسؤولة & 12 \\
\hline 59.5 & 2.975 & 0.996 & 1.88 & دعم الخطط الفاعلة لتنفيذ المنهاج السنوي لدرس التربية الرياضية & 1 \\
\hline 51.58 & 2.579 & 0.801 & 2.48 & تخصيص الحصص الكافية لدرس التربية الرياضية & 14 \\
\hline 58.86 & 2.943 & 0.764 & 2.63 & \multicolumn{2}{|c|}{ الدرجة النهائية لمستوى الإدارة المدرسية } \\
\hline
\end{tabular}

من ملاحظة جدول (5) يتبين إن المتوسطات الحسابية المرجحة تراوحت بين (2.323 ـ (4.357)، إذ حصلت الفقرة (2) على أعلى قيمة وبوزن مئوي بلغ (87.14)، والفقرة (10) حصلت على اقل قيمة للوسط المرجح وبوزن مئوي بلغ (46.46). أما الدرجة النهائية لمستوى محور (الإدارة المدرسية) فقد حصل على قيمة للوسط المرجح بلغت (2.943) وبوزن مئوي بلغ (58.86). ومن مراجعة الفقرات والنتائج التي حصلت عليها ينتين إن على الرغم من اهنمام مديريات التربية في اختبار مدرسي التربية الرياضية من خرجي كليات التربية البدنية وعلوم الرياضة بحسب قرارات وزارة التربية ومديرية التعيينات العامة في عدم إثنغال درس التربية الرياضية في المدارس إلا من ذوي الاختصاص، فضلاً عن التزام المديرية في تخصيص أوقات محددة لإقامة البطولات الدورية خلال السنة الدراسية، إلا إن الاشتراك فيها من قبل المدارس غير منتظم وذلك لقلة التتظيم والتتسيق لمدرسي التربية الرياضية في المدارس لترشيح الطلبة الأكفاء في أداء الألعاب الرياضية ولعدة أسباب فنية ومادية لا تسمح في التصرف بحرية من قبل المدرسين داخل المدرسة. وقلة الخطط المعتمدة في تفعيل درس التربية الرياضية لزخم الدروس الأخرى والوقت المتاح لإكمال متطلبات المنهاج السنوي لها، مما لا يسمح في تحديد خطط ناجعة لتطوير الدرس. إذ إن الإدارة المدرسية لا تعتمد ثقافة الجودة والتميز في منهاجها العام مما يؤثز سلباً على واقع الأداء للرياضة الددرسية. إذ يثير (ثوار فرنسيس 2000) إلى إن الجودة عملية إدارية تعتمد مجموعة من القيم والمعايير يتم تحقيقها في الميدان التربوي التي تسمح في إظهار المواهب وتتميتها من اجل

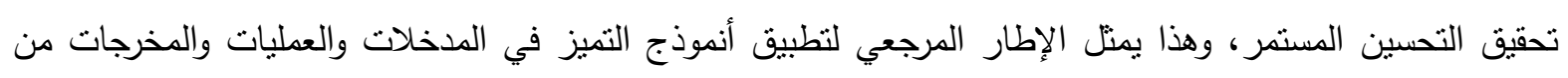
كافة الاتجاهات التربوية (5: 13 ـ 14). فضلاً عن ذلك إن الإدارة العليا لا ثُقعل عمل الدورات التدريبية لددرسي التخصص الرياضي لقلة التخصبص المالي وارتباط معظم المدرسين في الأمور الإدارية داخل المدارس مما بحول دون فاعلية درس التربية الرياضية في معظم المدارس. إذ يشير (رشيد طعيمة 2006) إلى إن التدريب أثناء الخدمة يؤدي إلى الى التى اكتساب المتدرب آفاقا جديدة في مجال مهنته والتبصر إلى المشكلات والتغيرات التي تطرأ وكيفية تلافيها، والإمام بالأساليب والطرائق الحديثة في مجال التعليم والتعلم والانفتاح على الزملاء من اجل تطوير العلاقات الاجنماعية وحسن القبادة والتتمية المهنية (7: 135). 
مجلة كلية التربية الرياضية - جامعة بغداد * المجلا الثامن والعثرون * العدد الرابع ** لسنة

• ثانياً: الميزانيات الداعمة للنشاط الرياضي: والمتضمن الفقرات من (15- 23).

جدول (6)

يبين نتائج الوسط الحسابي والانحراف المعيار والوسط المرجح والوزن المئوي لكل فقرة

\begin{tabular}{|c|c|c|c|c|c|}
\hline 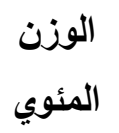 & المرجط & $\varepsilon^{ \pm}$ & سنَ & 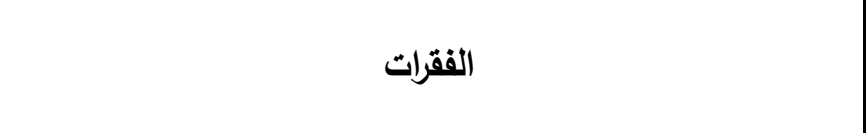 & 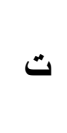 \\
\hline 44.98 & 2.249 & 742. & 1.94 & التتظيم والتتسيق للميزانية السنوية المخصصة للرياضة المدرسية & 15 \\
\hline 35.68 & 1.784 & 0.976 & 1.35 & توافر ميزانيات كافية لتفعيل درس التربية الرياضية & 16 \\
\hline 34.44 & 1.722 & 0.884 & 1.42 & الارياضة المدرسية من المنح المالية المقدمة من القطاعات الخاصة لدعم & 17 \\
\hline 35.12 & 1.756 & 0.799 & 1.59 & استثمار ملاعب المدرسة في النشاطات المدرسية المختلفة & 18 \\
\hline 67.34 & 3.367 & 0.352 & 3.87 & والعلاقات والطلابية السنوية مدرسية التربية الرياضية لأنشطة التعارف & 19 \\
\hline 35.26 & 1.763 & 0.792 & 1.23 & وفقاً لمواصفيص الأموال الكافية لتحسين وتطوير الملاعب الرياضية & 20 \\
\hline 35.48 & 1.774 & 0.809 & 1.05 & الرياضي العمال الدعم المادي والحوافز للمدرسين والطلبة لتحسين الأداء & 21 \\
\hline 35.7 & 1.785 & 0.855 & 1.13 & تدعم المدرسة النشاطات الداخلية والخارجية مالياً لتفعيل العمل & 22 \\
\hline 33.06 & 1.653 & 0.902 & 1.41 & خلال العام الدراسي الدرسة السفرات المدرسية للملاعب والقاعات الرياضية & 23 \\
\hline 39.67 & 1.983 & 0.790 & 1.66 & النهائية لمستوى الميزانيا: & ال الدرد \\
\hline
\end{tabular}

من ملاحظة جدول (6) يتبين إن المتوسطات الحسابية المرجحة تراوحت بين (1.653- 3.367)، إذ

حصلت الفقرة (19) على أعلى قيمة وبوزن مئوي بلغ (67.34)، والفقرة (23) حصلت على اقل قيمة للوسط المرجح وبوزن مئوي بلغ (33.06). أما الدرجة النهائية لمستوى محور (الميزانيات الداعمة للنشاط الرياضي) فقد حصل على قيمة للوسط المرجح بلغت (1.983) وبوزن مئوي بلغ (39.67). ومن مراجعة الفقرات والنتائج التي حصلت عليها ينبين إن مدرسي التربية الرياضية يتمتعون بروح الاندماج الاجتماعي واستقطاب الطلبة وانجذابهم نحو الألفة والتعارف والتقرب منهم من اجل التواصل خلال السنة الدراسية ومحاولة ضمان مشاركتهم بالفرق الطلابية وتمثيل المدرسة في البطولات الرياضية كنوع من النشاط المدرسي، ومحاولة استثمار اجتماعات المدرسة بأولياء الأمور والمناسبات الرسمية لتفعيل الانطباع المرن والايجابي لاكتساب محبة وتقة الطلبة وأولياء الأمور وحثهم نحو المشاركات الرياضية بشكل مستمر • إذ بـ عدت لمدرس التربية الرياضية واجبات مهنية تلقى على عاتقه من اجل الإيفاء بمنطلبات مهنته من خلال تتمية العلاقات 
مجلة كلية التربية الرياضية - جامعة بغداد * المجلا الثامن والعثرون * العدد الرابع * لسنة

الاجتماعية بين الطلبة واختيار التصرف المناسب لمواجه المشكلات التي تعوق أدائهم، وتوفير المشاركة الايجابية الفاعلة لكافة الطلبة لتحسين قابلياتهم الرياضية والبهجة والارتباح خلال اليوم الدراسي مما ينيح فرصة لتحقيق الغايات المنشودة من الأنشطة الطلابية في العام الدراسي (12: 65 ـ 66). بالمقابل يتبين إن هناك قصور من الناحية المادية الداعمة لتشجيع الددرس في تفعيل الدرس خلال العام الدراسي وعدم توافر الدعم المادي الكافي للإيفاء بمنطلبات الدرس بشكل متكامل يحقق الجودة العالية في الرياضة الددرسية، فضلاً عن الظروف الاقتصادية للجهات العليا بعدم توفير المبالغ المادية التي تسمح في إثراك الطلبة في سفرات رياضية إلى الملاعب والقاعات والأندية للتعرف على واقع الرياضة في البلد والى ما ترنو أليه التربية في إخراج لاعبين من المواهب المكتشفة من قبل مدرس الرياضة وزجها في هذا المضمار كنوع من الدعم الرياضي، فضلاً عن عدم تفعيل دور الاستثمار المدرسي أو استقطاب جهات داعمة لها من اجل الارتقاء بواع المدرسة بشكل عام والرياضة الددرسية على وجه الخصوص. إذ يثير (الجلبي والزيادات 2008) إلى إن تغطية التخصيص المالي لنفقات العمل المدرسي بكافة اتجاهاتها وتفعيل الموارد المالية داخلها يسمح في توفير فرصة لإثباع حاجات الطلبة توفير الإمكانات الكافية لإنجاح عملية التعليم والتعلم وتحقيق رغبات وميول الطلبة في ممارسة الأنشطة الترويحية والإفادة منها في تتمية الجوانب الإبداعية واكتثاف المواهب الرياضية الفنية وتتجيعهم على التطوير والتحسين المستمر لها (8: 170 - 171)

• ثالثاً: التخطيط لدرس التربية الرياضية: والمتضمن عدد الفقرات من (24 ـ 34).

جدول (7)

يبين نتائج الوسط الحسابي والانحراف المعيار والوسط المرجح والوزن المئوي لكل فقرة

\begin{tabular}{|c|c|c|c|c|c|}
\hline 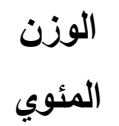 & الموجط & $\varepsilon^{ \pm}$ & سَن & 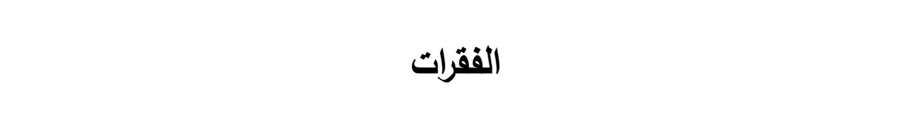 & ت \\
\hline 62.5 & 3.125 & 0.278 & 3.15 & الأداء الرياض تكنولوجيا منطورة لتحقيق سرعة الانجاز والدقة في تحسين & 24 \\
\hline 55.08 & 2.754 & 1.280 & 2.72 & تحديد أوقات درس التربية الرياضية خلال الجدول الأسبوعي بشكل & 12 \\
\hline 51.8 & 2.590 & 0.489 & 1.98 & اعتماد مناهج حديثة في تفعيل درس التربية الرياضية لمواكبة التطور & 26 \\
\hline 48.52 & 2.426 & 0.228 & 1.90 & استعمال الوسائل والتقنيات التعليمية في درس التربية الرياضية & 27 \\
\hline 53.6 & 2.680 & 0.233 & 1.77 & في التطبيق طرائق متعددة وحديثة في درس التربية الرياضية نظرياً وعملياً & 2 \\
\hline 64.36 & 3.218 & 0.331 & 3.19 & توافر الفرصة الكافية لمدرس التربية الرياضية في إظهار إمكاناته & 29 \\
\hline 48.84 & 2.442 & 0.442 & 1.22 & الأخبات مواعيد درس التربية الرياضية دون استغلال وتفضيل الدروس & 0 \\
\hline
\end{tabular}


مجلة كلية التربية الرياضية - جامعة بغداد * المجلا الثامن والعثرون * العدد الرابع ** لسنة

\begin{tabular}{|c|c|c|c|c|c|}
\hline 57.32 & 2.866 & 1.618 & 1.99 & المنهاج الرياضي المعتمد يوافق الإمكانات المنوافرة & 31 \\
\hline 63.34 & 3.167 & 1.372 & 3.70 & والنفحركية الريهاج الرياضي يلبي حاجات ومنطلبات الطلبة البدنية والعقلية & 32 \\
\hline 54.88 & 2.744 & 1.556 & 2.43 & اعتماد مبدأ التفوق والتميز في الأداء الرياضي & 33 \\
\hline 69.56 & 3.478 & 1.115 & 2.79 & نشجيع الطلبة على ممارسة الرياضة خارج أوقات الدوام الرسمي & 34 \\
\hline 57.25 & 2.862 & 0.812 & 2.44 & بة النهائية لمستوى التخطيط لدرس التربية الرياضية & \\
\hline
\end{tabular}

من ملاحظة جدول (7) يتبين إن المتوسطات الحسابية المرجحة تراوحت بين (2.426- 3.478)، إذ حصلت الفقرة (34) على أعلى قيمة وبوزن مئوي بلغة (69.56)، والفقرة (27) حصلت على اقل قيمة للوسط المرجح وبوزن مئوي بلغة (48.52). أما الدرجة النهائية لمستوى محور (التخطيط لدرس التربية الرياضية) فقد حصل على قيمة للوسط المرجح بلغت (2.862) وبوزن مئوي بلغة (57.25). ومن مراجعة الفقرات والنتائج التي حصلت عليها يتبين إن مدرسي التربية الرياضية يحاولون قدر الامكان الاهتمام بالأنشطة الرياضية والحث على ممارستها داخل وخارج المدرسة من خلال الارشاد التربوي، إذ تعد جزاً هاماً في تطوير وتحسين الأجهزة الفسيولوجية والتخلص من الإمراض وإكسابهم الصحة الجيدة، وقضاء أوقات الفراغ بشكل فاعل، يعود بالنفع على الطلبة بدنياً وعقلياً ونفسياً، فضلاً عن تقريغ الطاقات والحركة المفرطة في هذا العمر وابتعادهم عن كافة الاتجاهات السلبية التي تعوق نموهم العقلي والبدني. إذ يشير (عباس 1981) إلى إن النشاطات اللاصفية امتداد للنشاط الصفي ووسيلة لرقي الرياضة المدرسية، إذ إن ممارسة النشاطات الرياضية خارج أوقات الدوام الرسمي تعطي الفرصة في التحسين لمستوى القابليات والمواهب وتتمية الهويات الرياضية والنمو والتكيف الاجتماعي وتحسين العادات والسلوكيات والنضج الانفعالي، مما يتيح الفرصة بتطوير قدراته البدنية والعقلية وتوظيفها في الاتجاهات التربوية المرغوبة (9: 207 ـ 208). أما من ملاحظة باقي الفقرات يتبين هناك قصور في توافر التكنولوجيا الحديثة في تفعيل درس التربية الرياضية وقلة التقنيات والوسائل المساعدة، فضلاً عن عدم الاهنمام الكافي من قبل الإدارة المدرسية في اكتمال دروس التربية الرياضية وتفضيل باقي المواد الدراسية عليها وتكليف مدرسي التربية الرياضة بمهام أدارية خارج تخصصه المهني، وعدم وجود منهاج رياضي ثابت يطبق من قبل المدرسين والاعتماد على الخبرات الثخصية في اختبار المهارات والرياضات التي يمكن مزاولتها بحسب الإمكانات المتوافرة والأوقات المتاحة لتطبيق الدرس. إذ يعد التخطيط السليم والإدارة الفاعلة أساس في إنجاح الخطة السنوية في تحضير وتتظيم الدروس كافة تعريف الكوادر التدريسية بأدوارهم ومهامهم الدراسية بحسب التخصص والتتسيق في انتقال الطلبة من الدروس النظرية إلى نطبيق النشاطات الرياضة من خلال الجدول المعد مسبقاً على وفق نوقيتات زمنية تتاسب حاجات ومنطلبات تحقيق أهداف الرياضة المدرسية وتأهيله بشكل علمي وتربوي (13: 82 ـ 83). 
مجلة كلية التربية الرياضية - جامعة بغداد * المجلا الثامن والعثرون * العدد الرابع * لسنة

• رابعاً: الأبنية والتجهيزات المتوافرة: والمتضمن عدد الفقرات من (35 ـ 46).

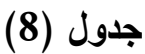

يبين نتائج الوسط الحسابي والانحراف المعيار والوسط المرجح والوزن المئوي لكل فقرة

\begin{tabular}{|c|c|c|c|c|c|}
\hline المئوي & المرجح & $\varepsilon^{ \pm}$ & سنَ & 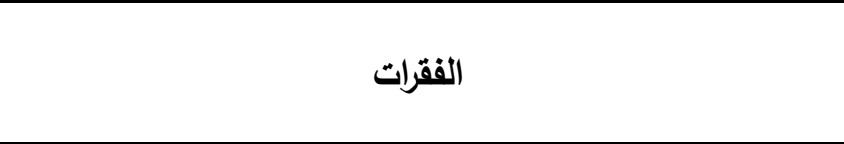 & $ت$ \\
\hline 28.7 & 1.435 & 0.762 & 1.56 & اعنماد مواصفات عالمية في تخصيص وبناء الملاعب الرياضية & 35 \\
\hline 54.44 & 2.722 & 1.988 & 2.76 & توافر الغرفة الخاصة لمدرسي التربية الرياضية & 36 \\
\hline 30.42 & 1.521 & 0.694 & 1.13 & توافر الملحقات الخدمية (حمامات ومنازع للطلبة بشكل كافي) & 37 \\
\hline 47.1 & 2.355 & 0.466 & 1.94 & توافر مخازن كافية للأجهزة والمعدات الرياضية & 38 \\
\hline 44.54 & 2.227 & 0.331 & 1.92 & توجد ساحات وملاعب كافية بالنسبة لعدد الطلبة في المدرسة & 39 \\
\hline 48.64 & 2.432 & 0.552 & 2.24 & توجد أجهزة ومعدات رياضية كافية التي تحقق المنهاج الرياضي & 40 \\
\hline 49.56 & 2.478 & 0.326 & 2.75 & الاهتمام بصيانة الملاعب وتخطيطها بشكل قانوني & 41 \\
\hline 25.3 & 1.265 & 0.348 & 1.31 & توافر قاعة الرياضية مغلقة في المدرسة & 42 \\
\hline 34.4 & 1.720 & 1.564 & 1.49 & توافر وسائل المتانة والأمان في الأجهزة والمعدات الرياضية & 43 \\
\hline 34.86 & 1.743 & 1.662 & 1.36 & نوافر المعدات الطبية والمستلزمات المتعلقة بالإسعافات الأولية & 44 \\
\hline 33.68 & 1.684 & 0.553 & 1.57 & اعنماد التجهيز من منشئ رصين & 45 \\
\hline 46.92 & 2.346 & 1.578 & 2.32 & اعتماد مقاييس قانونية للأجهزة والمعدات الرياضية & 46 \\
\hline 39.88 & 1.994 & 0.902 & 1.86 & النهائية لمستوى الأبنية والتجهيزات المتوافرة & 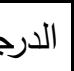 \\
\hline
\end{tabular}

من ملاحظة جدول (8) يتبين إن المتوسطات الحسابية المرجحة تراوحت بين (1.265 - 2.722)، إذ

حصلت الفقرة (36) على أعلى قيمة وبوزن مئوي بلغة (54.44)، والفقرة (42) حصلت على اقل قيمة للوسط المرجح وبوزن مئوي بلغة (25.3). أما الدرجة النهائية لمستوى محور (الأبنية والتجهيزات المتوافرة) فقد حصل على قيمة للوسط المرجح بلغت (1.994) وبوزن مئوي بلغة (39.88). ومن مراجعة الفقرات والنتائج التي حصلت عليها يتبين إن إجابات العينة متقاربة في تحديد كفاءة الأبنية وتوافر التجهيزات، إذ إن هناك إخفاق في تجهيز الأبنية الرياضية والملاعب على وفق المواصفات المعتمدة في المدارس عالمياً، وقلة الملاعب والساحات واستغلال أكثرها في توسيع الأبنية المدرسية وإهمال الملاعب الرياضية، فضلاً عن عدم اعتماد مواصفات رصينة ذات مواصفات قانونية في شراء وتجهيز الأدوات المستعطلة في النشاط والاكتفاء ببعض التجهيزات المتوافرة في الأسواق المحلية، وعدم اهتمام الجهات العليا في المديريات في توفير ما يلزم من المعدات لإنجاح الدرس والاعتماد على ما يخطط له المدرس في تلك المدرسة بحسب ما توافر من الأموال المخصصة والتجهيزات والملاعب الرياضية. إذ يؤكد (2007 Spillane) على أن مرونة المباني ومراعاة الشروط والمعايير الهندسية الرصينة فيها، وتحديد حجم الساحات والملاعب على وفق أعداد الطلبة للاستبعاب الكامل 
مجلة كلية التربية الرياضية - جامعة بغداد ** المجلا الثامن والعشرون ** العدد الرابع ** لسنة

وتوفير حصة دراسية ناجحة يساعد الطلبة في نطوير قابلياتهم العملية والاستفادة بقدر كافي من المناهج المطبق من قبل مدرسي التخصص الرياضي (19: 21 ـ 22). فضلاً عن نوافر التسهيلات والتمويل المالي يساعد في نتمية القدرات الرياضية وتطوير إمكانات الدرس للإفادة بأكبر قدر مدكن وإثباع حاجات وميول الطلبة من خلال منهج معد مسبقا في كيفية تسيير وتتفيذ المصروفات داخل المدرسة بوصفه احد أسباب تحقيق مرامي ونجاح المؤسسة التعليمية وتتفيذ الخطة والإيفاء بكافة المستلزمات والإمكانات المادية والمالية الداعمة لهذا النشاط (8: 173). • خامساً: المشاركات والجهات المستفيدة: والمتضمن عدد الفقرات من (47 ـ 56).

جدول (9)

يبين نتائج الوسط الحسابي والانحراف المعيار والوسط المرجح والوزن المئوي لكل فقرة

\begin{tabular}{|c|c|c|c|c|c|}
\hline 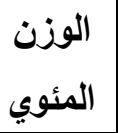 & الوسط & $\varepsilon^{ \pm}$ & سَن & الفقرات & ت \\
\hline 58.86 & 2.943 & 1.087 & 2.14 & الرياضي اعنماد خطط واضحة في تحقيق رضا الطالب وتطوير نشاطه & 47 \\
\hline 58.46 & 2.923 & 0.903 & 1.98 & المجمان جودة تحسين الأداء في الرياضة المدرسية وفقاً لمنطلبات & 48 \\
\hline 51.52 & 2.576 & 0.442 & 1.32 & إنشراك كافة الأطراف في التخطيط والتعديل للمنهاج الرياضي & 49 \\
\hline 33.08 & 1.654 & 0.832 & 1.25 & الرياضة المدرسية المقايي المرجعية والمعايير العالمية في تطوير مجالات & 50 \\
\hline 57.26 & 2.863 & 0.235 & 1.89 & وضع خطط فاعلة لاكتثاف المواهب وتطويرها & 51 \\
\hline 71.34 & 3.567 & 0.437 & 3.45 & والميول والاتجاهات والتفاعل الايجابي مع الطلبة للتعرف على الحاجات & 52 \\
\hline 54.74 & 2.737 & 0.547 & 2.37 & الاستماع إلى أراء وشكاوى الطلبة وأولياء الأمور بشكل مستمر & 53 \\
\hline 53.08 & 2.654 & 0.579 & 2.48 & التربية الرياضية العلاقات الاجتماعية بين المدرسة والمجتمع لتفعيل درس & 54 \\
\hline 43.08 & 2.154 & 0.976 & 1.85 & واقع الرياضمال كافة الوسائل العملية لجمع المعلومات والبيانات لتحسين & 55 \\
\hline 53.78 & 2.689 & 1.763 & 2.17 & المرتفيدين وتطلعاتهر استراتيجيات العمل لمواجهة المتغيرات في مطالب & 56 \\
\hline 53.52 & 2.676 & 0.780 & 2.09 & النهائية لمستوى المشاركات والجهات المستقيدة & \\
\hline
\end{tabular}


مجلة كلية التربية الرياضية - جامعة بغداد * المجلا الثامن والعثرون * العدد الرابع * لسنة

من ملاحظة جدول (9) يتبين إن المتوسطات الحسابية المرجحة نراوحت بين (1.654- 3.567)، إذ حصلت الفقرة (52) على أعلى قيمة وبوزن مئوي بلغة (71.34)، والفقرة (50) حصلت على اقل قيمة للوسط المرجح وبوزن مئوي بلغة (33.08). أما الدرجة النهائية لمستوى محور (الأبنية والتجهيزات المنوافرة) فقد حصل على قيمة للوسط المرجح بلغت (2.676) وبوزن مئوي بلغة (53.52). ومن مراجعة الفقرات والنتائج التي حصلت عليها يتبين إن قلة إثراك كافة الأطراف المعنية في تحديد الخطط والمنهاج الرياضي خلال السنة الدراسية يحول دون نطوير الدرس، وعدم اعتماد منهاج رئيس في تحديد الخطة الرياضية ضمن المنهاج الدراسي السنوي في المدرسة والاعتماد على الخبرات الثخصية للمدرس في توفير العاب رياضية قليلة لعدم اكتمال نصاب الدروس واستغلالها في تغطية المناهج الدراسي لبقية المواد، وعدم إثراك الأطراف المجتمعية في إبداء الرأي بما بخدم العملية التعليمبة والاقتصار على ما تحدده الجهات العليا من دروس وأوقات زمنية في نطبيقها يؤثز سلباً في تطوبر إمكانات العمل الرياضي وقلة رفد المجتمع بالإمكانات الطلابية وتكملة مسيرتهم في هذا الاتجاه كجانب مهم في رفد المجتمع وتطوير البلدان. فضلاً عن قلة المقاييس المرجعية التي ينضوي تحتها العديد من برامج التطوير والوصل على ما سبق في هذا المجال وجعله محك يستتد إليه في التطوير والارتقاء بالواقع الرياضي في المدارس العراقية. إذ يرى (الثافعي 2003) إن كل عمليات المشاركة في التخطيط والبناء تعطي فرصة بنجاح العمل المدرسي بكافة جوانبه النظرية والعملية، والإفادة من التقويم المستمر في ضوء معايير محددة يسهم في رفع الكفاءة المهنية للمدرسين والقدرات الرياضية للطلبة، فضلاً عن الاستماع بشكل مستمر إلى كافة الأطراف المستفيدة من مخرجات المدرسة ومعرفة أراءهم بما يحقق المرامي التي تتطلع إليها هذه الأطراف من اجل التحسين المستمر لقرات ومواصفات الطلبة بما يخدم تطلعات وفلسفة الدولة (6: 56 ـ 57).

\section{3-4}

للتعرف على الفروق في فاعلية تطبيق درس التربية الرياضية بين مدارس تربيات بغداد الكرخ الأولى

والثانية، والوقوف على إجابات العينة، عد الباحث إلى حساب الوسط الحسابي والانحراف المعياري وقيمة (ت)

المحسوبة والمعنوية الحقيقية لكل محور من محاور الاستبانة وكما في جدول (10).

جدول (10)

يبين نتائج الاختبار التائي لعينتين مستقلتين غير متساويتين بالحجم لكل محور بحسب إجابات تربيات الكرخ الأولى جلى والثانية في بغداد

\begin{tabular}{|c|c|c|c|c|c|c|c|c|}
\hline الدالة & لمقنوية لحقية & المحسوية & $\varepsilon^{ \pm}$ & سَ س & علد العينة & الفقرات & المحور الرئيس & $ت$ \\
\hline \multirow{2}{*}{ غير دالة } & \multirow{2}{*}{0.765} & \multirow{2}{*}{2.543} & 38.936 & 34.452 & 56 & \multirow{2}{*}{14} & \multirow{2}{*}{ الإدارة المدرسية } & \multirow{2}{*}{ أولا } \\
\hline & & & 54.253 & 44.276 & 67 & & & \\
\hline \multirow{2}{*}{ غير دالة } & \multirow{2}{*}{1.457} & \multirow{2}{*}{5.234} & 22.891 & 19.656 & 56 & \multirow{2}{*}{9} & \multirow{2}{*}{ الرياضينيات الداعمة للنشاط } & \multirow{2}{*}{ ثنانياً } \\
\hline & & & 15.432 & 24.154 & 67 & & & \\
\hline
\end{tabular}


مجلة كلية التربية الرياضية - جامعة بغداد * المجلا الثامن والعثرون * العدد الرابع ** لسنة

\begin{tabular}{|c|c|c|c|c|c|c|c|c|c|}
\hline \multirow{2}{*}{ غير دالة } & \multirow{2}{*}{0.637} & \multirow{2}{*}{0.452} & 20.865 & 22.655 & 56 & \multirow{2}{*}{11} & \multirow{2}{*}{\multicolumn{2}{|c|}{ الترياضية }} & \multirow{2}{*}{ ثالثا } \\
\hline & & & 23.275 & 25.762 & 67 & & & & \\
\hline \multirow{2}{*}{ غير دالة } & \multirow{2}{*}{1.578} & \multirow{2}{*}{1.773} & 24.326 & 26.546 & 56 & \multirow{2}{*}{12} & \multirow[t]{2}{*}{ والتجهيزات } & & \multirow{2}{*}{ رابعاً } \\
\hline & & & 31.549 & 23.651 & 67 & & & المتوافرة & \\
\hline \multirow{2}{*}{ غير دالة } & \multirow{2}{*}{0.714} & \multirow{2}{*}{0.261} & 20.237 & 19.996 & 56 & \multirow{2}{*}{10} & \multirow[t]{2}{*}{ والجهات } & المشاركات & \multirow{2}{*}{ خامساً } \\
\hline & & & 29.664 & 21.878 & 67 & & & المستقيدة & \\
\hline
\end{tabular}

$0.05 \geq$ (sig) معنوي إذا كانت المعنوية الحقيقية

جدول (11)

يبين نتائج الاختبار التائي لعينتين مستقلتين غير متساويتين بالحجم

\begin{tabular}{|c|c|c|c|c|c|c|c|c|}
\hline مدائ|c| \\
\hline
\end{tabular}

0.05 > معنوي إذا كانت المعنوية الحقيقية (sig)

يتبين من ملاحظة جدول (10 ـ 11) للمحاور الرئيسة وبعد مقارنة قيمة المعنوية الحقيقية بمسنوى الدلالة

البالغة (0.05) اتضح عدم وجود فروق ذات دلالة إحصائية، أي إن تربيات الكرخ الأولى والثانية لا تختلف في نقييمها لفقرات الاستبانة بحسب الاجابات التي نم استحصالها من عينة التطبيق، إذ إن الجهتين تقع على عاتقها نفس التعليمات والأنظمة التي تصدرها الجهات العليا في الوزارة، فضلاً عن التمويل والتجهيز يكون ضمن نطاق موحد لكافة المدارس على الرغم من وجود بعض الاختلافات بحسب أعداد الطلبة والمدرسين المتواجدين فيها، مما لا يؤثز في القدرة على تفوق الواحدة دون الأخرى في درجة فاعلية تطبيق درس التربية الرياضية. على الرغم من ملاحظة وجود بعض الفوارق الطفيفة والتي تعزى إلى الإمكانات الثخصية لمدرسي المادة في إنجاح فاعلية الدرس من خلال الخبرات المنوافرة لديهم وبعض التجهيزات التي يوفرها بشكل شخصي لتعليم الطلبة وتطوير ممارستهم للرياضة بشكل عام. 
مجلة كلية التربية الرياضية - جامعة بغداد * المجلا الثامن والعثرون * العدد الرابع * لسنة

5- الباب الخامس: الاستتتاجات والتوصيات:

1-5 1-5 الاستتتاجات:

1. تعتمد مديريات النشاط الرياضي على ذوي الاختصاص فقط في درس التربية الرياضية. 2. ضعف المعايير المستخدمة في التعرف على واقع فاعلية درس التربية الرياضية وقلة الجهاز المشرف على عمليات التقويم السنوي وبشكل مستمر .

3. قلة الأماكن المخصصة لنطبيق درس التربية الرياضية واستغلالها في نطوير الابنة المدرسية لأغراض تربوية أخرى.

4. النظرة السلبية من قبل الإدارة المدرسية وأولياء الامور في انشغال الطلاب عن أداء واجباتهم المدرسية والابتعاد عن الأهداف التزبوية بحسب وجهة نظرهم.

5. قلة توافر التمويل المالي لاعم برنامج الرياضة المدرسية والاكتفاء ببعض الألعاب بحسب إمكانات الددرسة. 6. قلة الكوادر التدريسية في مجال التخصص الرياضي في بعض المدارس، فضلاً عن تكليفهم بمهام تربوية أخرى. 7. قلة الاهتمام بدرس التربية الرياضية خلال اجتماع أولياء الأمور والتركيز على الدروس التربوية الأخرى.

2-5

1. الآخذ بنظر الاعتبار آراء المستفبد الداخلي (المدرسين، الطلاب) والخارجي (المجتمع، اولياء الامور) في دعم وتطوير واقع الرياضة المدرسية.

2. إجراء دراسات مقارنة مع باقي المحافظات من خلال الاستبانة المعدة والاستفادة من النتائج البحث الحالي. 3. تطوير الكوادر التدريسية في مجال التخصص الرياضي من خلال الدورات التدريبية والتنقيفية لدعم الواقع التربوي.

4. اعتماد منهاج تدريسي خلال السنة الدراسية يتضمن برنامج رياضي متكامل وبحسب أهداف كل مرحلة. 5. المشاركات المجنمعية والاندماج مع الجهات المناظرة بشكل مستمر لتطوير العلاقات والاتصال وثبادل الخبرات

الرياضية.

6. اعتماد مبدأ محاسبة المقصرين في واجباتهم من المدراء والمدرسين والمشرفين.

7. الاهنمام في تفعيل درس التربية الرياضية في منوسطات واعداديات تربيات الكرخ (الاولى، الثانية) للبنين 


\section{مجلة كلية التربية الرياضية - جامعة بغداد ** المجلا الثامن والعثرون ** العدد الرابع ** لسنة}

\section{المصادر العربية والأجنبية:}

1. إبراهيم حنفي شعلان؛ معوقات أهداف التربية الرياضية بدولة الإمارات العربية المتحدة، موسوعة بحوث التربية البدنية والرياضية بالوطن العربي في القرن العشرين،ج3،13،(عمان، دار المناهج للنشر والتوزيع، 2001).

2. أسير مجدي؛ المشكلات المهنية التي تواجه مدرسي التربية الرياضية في المدارس الحكومية، رسالة ماجستير، كلية التربية الرياضية للبنين، جامعة حلوان، 2008).

3. أمين أنور الخولي وجمال الدين الثافعي؛ مناهج التربية البدنية المعاصر، (القاهرة، دار الفكر العربي، 2005). بسام عباس البياتي؛ الصعوبات التي تواجه الرياضة المدرسية في العراق عن طريق الواقع الحقيقى للاتجاهات الحديثة للرياضة المدرسية، (بغداد، ب س، 1998).

5. ثوار فرانسيس وكارل جي؛ ثلاثية إدارة الجودة الثاملة (سلسلة الايزو، جائزة ديمنج، معايير بالدرج) ،ط2: ترجمة عبد الحكيم احمد الخزامي، (القاهرة، دار الفجر للنشر والتوزيع، 2000).

6. حسن احمد الثنافع؛ التشريعات في التربية البدنية والرياضية ــ القوانين واللوائح التنظيمية والإدارية للنقابة والمؤسسة الرياضية، ط1 (الإسكندرية، دار الوفاء للطباعة والنشر، 2003). رشيد احمد طعيمة؛ المعلم وكفاياته وإعداده، ط2 (القاهرة، دار الفكر العربي، 2006). .7

8. سوسن الجلبي ومحمد عواد الزيادات؛ الجودة في التعليم دراسة تطبيقية، (عمان، دار صفاء للنشر والطباعة، .$(2008$

عباس احمد صالح؛ طرائق التدريس في التربية الرياضية، ج1 (الموصل، مؤسسة دار الكتب للطباعة والنشر، .9

10. عفاف عبد اله الكاتب وآخرون؛ دليل مدرس التربية الرياضية (المرحلة متوسطة)، ط1 (العراق، مطبعة الثركة العامة للسكاير، 2012). 11. فاتن غانم خليل؛ واقع النشاط الرياضي اللاصفي الداخلي وسبل تطويره على مدارس المتوسطة للبنات في بغداد، رسالة ماجستير ، جامعة بغداد، كلية التربية الرياضية، 1993. 12. كريم ناصر علي واحمد محد مخلف؛ الإدارة الصفية، (عمان، مطبعة الثروق، 2006). 
مجلة كلية التربية الرياضية - جامعة بغداد * المجلد الثامن والعشرون ** العدد الرابع ** لسنة

13. محمد زياد حمدان؛ التعليم المدرسى ـ تحفيزه وادارته وقياسه التربوي، (عمان، دار التربية الحديثة، 2000). 14. محمود عبد الفتاح وآخرون؛ التربية الرياضية المدرسية، (القاهرة، دار الفكر العربي، 1998).

15. مكارم حلمي أبو هرجه ومحمد سعد زغلول؛ مناهج التربية الرياضية، ط1 (القاهرة، مركز الكتاب للنشر، 1999).

16. ممدوح عبد المنعم وعيسى عبد الله؛ القياس والتقويم النفسى والتربوي، ط1 (الإمارات، مكتبة الفلاح للنشر والتوزيع، 1995).

17. هاني العمري؛ منظور الجودة في قطاع التعليم، المنهجية والتطبيق، (جدة، المجلس السعودي للجودة، 2002).

18. Ebel, R; Essentials of Education measurement: (Engle wood, cliffs, new york, prentice-hall,1972)

19. Spillane, Jame. "Eduational leadership" Educational Evaluation and poliysis Voi, 2004. 
مجلة كلية التربية الرياضية - جامعة بغداد ** المجلد الثامن والعشرون * العدد الرابع * لسنة

\section{ملحق رقم (1)}

أسماء المقابلات الشخصية في المجال الرياضي والإشراف التربوي ومدراء ومعوني المدارس

\begin{tabular}{|c|c|c|c|}
\hline مكان العمل & التخصص & 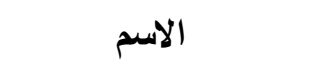 & $ت$ \\
\hline إعدادية المحبة للبنين & مدير مدرسة & سليمان عبد الرزاق علي & 1 \\
\hline إعدادية زين العابدين للبنين & مدير مدرسة & بهاء كريم جابر & 2 \\
\hline اعدادية الداوودي للبنين & مدير مدرسة & جمال خالد امين & 3 \\
\hline منوسطة ابن الهيثم للبنين & مدير مدرسة & جبار علي علاوي & 4 \\
\hline منوسطة بغداد للبنين & مدير مدرسة & خلدون محمد فالح & 5 \\
\hline متوسطة الانتفاضة للبنين & مدير مدرسة & سرحان كليفح حمد & 6 \\
\hline إعدادية زين العابدين للبنين & معاون مدير & صبيح حسين محمد & 7 \\
\hline إعدادية المحبة للبنين & معاون مدير & علي فرهود & 8 \\
\hline مديرية النشاط الرياضي / الكرخ الثانية & مشرف نزبوي & خليل رحيم علي & 9 \\
\hline مديرية النشاط الرياضي / الكرخ الثانية & مشرف نربوي & وجدان هادي عبد & 10 \\
\hline مدرية النشاط الرياضي / الكرخ الاولى & مشرف نربوي & خالد عبد الله رحيمة & 11 \\
\hline مديرية النشاط الرياضي / الكرخ الاولى & مشرف نربوي & وميض مجيد محمد & 12 \\
\hline المديرية العامة للتربية الرياضية وزارة التربية & مشرف نربوي & مؤيد اسماعيل عبد & 13 \\
\hline المديرية العامة للتربية الرياضية وزارة التربية & مشرف نربوي & مثتى علي نعمة & 14 \\
\hline المديرية العامة للتربية الرياضية وزارة التربية & مشرف تربوي & فاتن غانم خليل & 15 \\
\hline
\end{tabular}


مجلة كلية التربية الرياضية - جامعة بغداد * المجلا الثامن والعشرون * العدد الرابع * لسنة

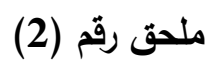

أسماء الخبراء المختصين في المجال الرياضي

\begin{tabular}{|c|c|c|c|}
\hline مكان العمل & التخصص & 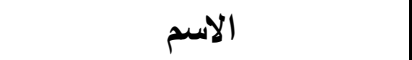 & $\ddot{ت}$ \\
\hline | جامعة بغداد / قسم النشاط الرياضي & اختبارات وقياس & | ا.د. ثنائر داوود سلمان & 1 \\
\hline |جامعة بغداد / كلية التربية البدنية وعلوم الرياضة & طرائق تدريس & ا ا.د. اسماعيل محمد رضا & 2 \\
\hline الجامعة المستتصرية / كلية التربية الاساسية & طرائق تدريس & ا.د. نبيل عبد الوهاب احمد & 3 \\
\hline الجامعة المستتصرية / كلية التربية الاساسية & قياس واختبارات & |.د. محجوب ابراهيم ياسين & 4 \\
\hline الجامعة المستتصرية / كلية التربية البدنية وعلوم الرياضة & علم النفس الرياضي & | ا.د. ماهر عواد محمد & 5 \\
\hline |جامعة بغداد / كلية التربية البدنية وعلوم الرياضة & علم النفس الرياضي & ا ا.د. عبد الله هزاع الثافعي & 6 \\
\hline الجامعة المستتصرية / كلية التربية الاساسية & طرائق تدريس & ا.د. اسماعيل عبد زيد & 7 \\
\hline |جامعة بغداد / كلية التربية البدنية وعلوم الرياضة & علم النفس الرياضي & ا.م.د. هلال عبد الكريم صالح & 8 \\
\hline |الجامعة المستتصرية / كلية التربية الاساسية & 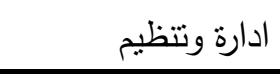 & ا ام.د. صلاح وهاب شاكر & 9 \\
\hline جامعة بغداد / كلية التربية البدنية وعلوم الرياضة للبنات & طرائق تدريس & ا.م.د. نهاد محمد علوان & 10 \\
\hline | وزارة التربية / قسم ضمان الجودة & 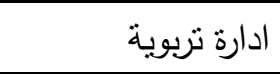 & ا .م.د. عبد الرحمن مال الله & 11 \\
\hline | وزارة التربية / المديرية العامة للتربية الرياضية & اختبارات وقياس & ا ا.م.د. فاتن غانم خليل & 12 \\
\hline جامعة بغداد / كلية التربية البدنية وعلوم الرياضة للبنات & طرائق تدريس & ا ا.م.د. نجلاء عباس & 13 \\
\hline مزارة التربية / المديرية العام للتربية الرياضية & علم النفس الرياضي & م م.د. سعد خميس & 14 \\
\hline
\end{tabular}


مجلة كلية التربية الرياضية - جامعة بغداد * المجلا الثامن والعشرون * العدد الرابع * لسنة

ملحق رقم (3)

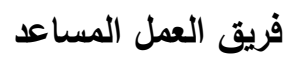

\begin{tabular}{|c|c|c|c|}
\hline مكان العمل & التخصص & 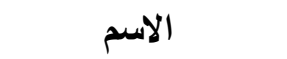 & $ت$ \\
\hline جامعة بغداد / مركز الجامعة & دكتوراه / تربية رياضية & مهند طالب عبد & 1 \\
\hline جامعة بغداد / كلية التربية البدنية وعلوم الرياضة & مدرس / تربية رياضية & خليل ستار محمد & 2 \\
\hline جامعة بغداد / مركز الجامعة & مدرس مساعد / تربية رياضية & منتظر محمد مغامس & 3 \\
\hline إعدادية المحبة للبنين & معاون مدير & علي فرهود & 4 \\
\hline قسم الاعداد والتدريب / الكرخ الثانية & دكتوراه / مشرف تربوي & حيدر نوار حسين & 5 \\
\hline قسم الاعداد والتدريب / الكرخ الثانية & مدرس مساعد/ مشرف تربوي & اياد محمد احمد & 6 \\
\hline متوسطة الفردوس للبنين & مدير مدرسة & فائز ابراهيم سرداح & \\
\hline منوسطة البساط الاخضر للبنين & مدير مدرسة & علي ابراهيم محمد & \\
\hline إعدادية زين العابدين للبنين & معاون مدير & صبيح حسين محمد & 7 \\
\hline اعدادية الداوودي للبنين & معاون مدير & 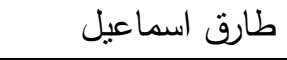 & 8 \\
\hline |عدادية الرشيد للبنين & مدرس رياضة & احمد محمد علي & 9 \\
\hline اعدادية المثثى للبنين & مدرس رياضة & خالد حسين سنيد & 10 \\
\hline متوسطة الفردوس للبنين & مدرس رياضة & ميزر عريبي & 11 \\
\hline متوسطة الفردوس للبنين & مدرس رياضة & نجاح حميد محجوب & 12 \\
\hline
\end{tabular}

